\title{
A PRÁTICA DE ANÁLISE LINGUÍSTICA: DIÁLOGO ENTRE PROFESSOR X TEXTO X ESCRITOR
}

\author{
THE PRACTICE OF LINGUISTIC ANALYSIS: DIALOGUE BETWEEN TEACHER X \\ TEXT X WRITERS
}

\author{
Silvane Aparecida de Freitas ${ }^{1}$ \\ silvaneafreitas@hotmail.com
}

\begin{abstract}
RESUMO: Consideramos que não há atividade melhor para levar o aluno a agir e refletir com e sobre a linguagem do que levar o estudante a perceber as diversas maneiras de dizer o mesmo. No meio escolar, essas atividades são denominadas de Atividades de Análise Lingüística (GERALDI, 1984), termo que surgiu para denominar uma nova perspectiva de reflexão sobre o sistema lingüístico e sobre os usos da língua, com vistas ao tratamento escolar de fenômenos gramaticais, textuais e discursivos. Partindo desses pressupostos, pretendo analisar como um professor do $5^{\circ}$ ano do ensino fundamental encaminha as atividades de refacção textual. Esse professor aponta apenas para a correção de aspectos pontuais do texto, ou trabalha de uma forma discursiva encaminhando para ampliação de idéias, informatividade, argumentação e coerência?
\end{abstract}

PALAVRAS-CHAVE: análise linguística; diálogo; produção textual; leitura; professor.

ABSTRACT: We consider that there is not better activity for lead the student act and reflect with and about the language than lead the student it perceive the diverse ways of say the even. In the school environment, those activities are named of activities of Linguistic Analysis (GERALDI, 1984), term that arose for name a new perspective of reflection about the linguistic system and about the uses of the language, with an aim to the school handling of textual, grammatical phenomena and discursivos. Starting from those budgets, I want to in this communication analyze like a teacher of the $5^{\circ}$ year of the elementary school guides education directs the activities of refacção text, as gives the dialogue between professor $x$ text $x$ writer (producing of the text). The teacher points only for the correction of specific aspects of the text, or works in a discursive forwarding to the expansion of ideas, information, line of argument and coherence?

KEY WORDS: linguistic analysis; dialogue; textual production; reading; teacher.

\section{Introdução}

As considerações tecidas nesta pesquisa serão formuladas por um sujeito que ocupa um lugar numa determinada conjuntura sócio-histórica, cuja prática discursiva é condicionada por filtros diversos: conhecimentos, sistemas de crenças, representações ideológicas e tábuas de valores. Dentro desses princípios, a linguística e o ensino de língua materna têm mobilizado minha atenção e feito parte de minha história de vida enquanto profissional do ensino de língua e ser humano que sou.

\footnotetext{
${ }^{1}$ Professor Adjunto da Universidade Estadual de Mato Grosso do Sul e Pesquisador Colaborador do IEL/UNICAMP
} 
Entendo que a linguagem é uma atividade constitutiva: é pelo processo de internalização do que nos era exterior que nos constituímos como sujeitos que somos, e, com as palavras de que dispomos, trabalhamos na construção de novas palavras. A língua é vista como um conjunto de recursos expressivos, não fechado e sempre em constituição.

A partir dessas identificações e dentro de uma perspectiva sócio-histórica, que considera o ensino na sua dialogicidade e que o sujeito se constitui na e pela linguagem, procurarei verificar o lugar atribuído à prática de análise linguística em sala de aula. Mais precisamente, pretendo analisar como um professor do $5^{\circ}$ ano do ensino fundamental encaminha as atividades de refacção textual; como se dá o diálogo entre professor x texto $x$ escritor (produtor do texto). Esse professor aponta apenas para a correção de aspectos pontuais do texto, ou trabalha de uma forma discursiva encaminhando para ampliação de idéias, informatividade, argumentação e coerência? E o aluno/escritor como responde aos encaminhamentos do professor? O que ele muda na segunda versão?

\section{Ensino de língua materna e a prática de análise linguística}

Sabemos que o ensino gramatical (gramática de frases e de nomenclatura), ainda, tem sido um dos fortes pilares do currículo de ensino de Língua materna em nossas escolas, tanto no ensino fundamental como no médio.

Com o surgimento de novos paradigmas científicos nos finais do século XIX, as línguas começam a ser consideradas como objetos de conhecimento. Essa mudança de perspectiva tem a preocupação de definir o objeto-língua e o esforço de elaborar métodos para descrever esse objeto com o máximo de rigor. As regras gramaticais passam a ser consideradas como reflexo da linguagem. Com isso, a terminologia gramatical tradicional, também, vai sofrer alteração: em vez de partes do discurso, fala-se de categorias gramaticais, de classes, de funções sintáticas. Nesse período que se prolonga até hoje, a frase é o objeto de reflexão e do ensino gramatical. É assim com a teoria estrutural, é assim com a teoria gerativa. (FIGUEIREDO, 2005).

Posteriormente a essas correntes, segundo esta pesquisadora, as teorias da enunciação e das gramáticas textuais trouxeram seus contributos. O apelo à atividade reflexiva do aluno, que se ficava pelo sistema da língua, terá agora de se fazer sobre a diversidade de seus usos. Em oposição ao dogmatismo das regras, ativa-se e adota-se agora o estudo de curiosidade e de pesquisa: formular hipóteses, verificá-las, construir pelo raciocínio um percurso científico de construção gramatical. 
A partir dos anos 80, no Brasil, temos em circulação uma perspectiva de ensino de entender o ensino de língua, a um só tempo operacional e reflexivo, assumida por Geraldi (1984, 1993, 1996) e Franchi $(1977,1987)$, entre outros, partindo da reflexão sobre o modo como o sujeito constrói conhecimento sobre a língua.

Essa corrente insiste em um deslocamento radical dos papéis de aluno e professor, que deixam de ser funções que se exercem no interior da escola e passam à condição plena de interlocutores, assim como no privilégio de uso efetivo da língua, já que só aprende língua na medida em que operando com ela, comparam-se expressões, experimentando novos modos de construção e, investindo nas formas linguísticas de significação. (BRITTO, 1997).

Assim, temos, mais precisamente com Geraldi (1984), uma reorientação do ensino de língua materna, com base na leitura e escrita de textos como práticas sociais significativas e integradas, e na análise dos problemas encontrados na produção textual como mote para a prática da análise linguística, em vez de exercícios estruturais de gramática (normativa e descritiva).

Mediante tais concepções de língua e de ensino, vem-se firmando um movimento de revisão crítica do ensino de língua, ou seja, vem-se questionando a validade de um ensino centrado na gramática e pela gramática, o que faz emergir a proposta de análise linguística $(A L)$, em vez de aulas de gramática, tendo como princípio a ampliação da competência comunicativa-discursiva dos indivíduos em fase de escolarização.

Segundo Figueiredo (2005), preparar o aluno para a reflexão linguística, levando-o a formular hipóteses e as verificar, construindo e reconstruindo a língua, é prepará-lo para o hábito de se questionar sobre a língua e sobre a comunicação por meio da prática da observação. Para isso,

[...] o aluno precisa produzir e reproduzir os seus próprios textos, comentálos e reescrevê-los. Assim, a sua competência gramatical vai-se adquirindo na prática da escrita-leitura e na reflexão sobre o funcionamento da língua aquando na produção-recepção de textos, sejam eles orais ou escritos. (FIGUEIREDO, 2005, p. 109).

É função da escola/professor ampliar o saber linguístico que esse aluno já tem consigo. É na escola que muitos de nossos alunos terão a única chance de ter contato direto com as convenções da escrita e com os diversos gêneros textuais. Por isso, é de suma importância que os professores da área de Língua Portuguesa assumam seu 
verdadeiro papel, que é o de propiciar condições para que os alunos saibam fazer uso adequado de nossa língua conforme a situação sócio-interativa.

Partindo dessa concepção, seria necessário, que o professor de língua materna se preocupasse em desenvolver competências em seus alunos. Neste contexto, a competência assinala, segundo Figueiredo (2005, p. 37), um ser que sabe e que tem aptidões para fazer e manipular qualquer coisa com finalidade. No caso de essa "coisa" ser a língua, o sujeito competente é aquele que é capaz de interpretar e produzir discursos escritos e orais em situações de comunicação diversas (incluindo o discurso estético, formal e informal). E baseando-se em Dolz e Bronckart (2000), essa pesquisadora (p. 38) argumenta que delimitar a noção de competência ao domínio do ensino/aprendizagem de língua materna é delimitá-lo ao inventário das capacidades linguísticas que se traduzem sempre por capacidades de ação, capacidades discursivas e capacidades linguístico-discursivas.

Sabemos que há normas a serem aprendidas pelo aluno e usadas na escrita de textos, tais como: pontuação, escrita correta das palavras, maiúsculas, segmentação de palavras, frases e parágrafos, adequação dos tempos verbais. Ao professor caberá explicitá-las, por meio de atividades de linguagem (muita leitura/releitura), de reflexão e operação sobre a linguagem (reescrita de textos, reestruturação de frases e parágrafos) e não de metalinguagem (ensino de nomenclatura). Restringir-se, pois, à sua gramática é limitar-se a um de seus componentes apenas. É perder de vista sua totalidade e, portanto, falsear a compreensão de suas múltiplas determinações. (ANTUNES, 2007).

Assim, é desejoso que o professor de língua materna não faça do conhecimento gramatical o único fundamento de sua autoridade, até porque a língua excede a gramática. (ILARI \& BASSO, 2006, p. 234). O professor de língua materna precisa estar preparado para levar o aluno para além da função simplista da linguagem, ele precisará não só motivar a expressão oral e escrita, mas também e, sobretudo, explicitar a articulação entre situações motivadoras que cria e as marcas que correlativamente surgem nos enunciados oral e escrito, nas suas diversas modalidades e variantes, dialógicas e não dialógicas. "Produção e análise de discursos constituirão, pois, as actividades básicas na aula de língua materna". (FONSECA \&, 1994, p. 155, grifos da autora).

Uma análise desse tipo, segundo Fonseca \& Fonseca (1977), vai condicionar (e ser pressuposto) a produção, e o produto assim obtido pode depois, por sua vez, ser analisado. 
Análise e produção de textos constituem-se assim como dois momentos complementares da actividade didáctica na sala de língua materna, situando-se como dois pólos de um mesmo processo pragmático: no primeiro caso, parte-se do texto a analisar para uma reconstituição das coordenadas situacionais e da sua adequação a elas; no segundo caso, parte-se das situações para levar a uma (re) criação do texto, a uma produção que procure adequar-se às circunstâncias previamente dadas. (FONSECA \& FONSECA, 1977, p. 123).

Nesta ordem de idéias, o texto, segundo esses autores, deverá ser sempre encarado, na aula de Português, antes de todo e qualquer tipo de utilização, como produto de um ato de fala, como discurso, isto é como enunciado que traz em si as marcas do processo de enunciação, da adequação às finalidades próprias do momento de comunicação, das várias ações cumulativamente desenvolvidas em cada ato verbal. "A análise de textos, na aula de Português, terá, pois, de ser, antes de mais nada, uma análise da especificidade dos discursos".(FONSECA \& FONSECA, 1977, p. 107).

Para esta pesquisadora (1994), é preciso inscrever o comportamento verbal no quadro do comportamento global. No entanto, isso não pode significar que a pedagogia da língua materna deixe de ter um caráter predominantemente linguístico. O estudo dos textos terá, pois, como objetivo central, na pedagogia da língua materna, suscitar no aluno a consciência dos recursos múltiplos da língua e conduzi-lo à exploração desses recursos para a obtenção de uma melhor adequação às circunstâncias que determinam a especificidade tipológica dos discursos.

A pedagogia da língua materna torna-se, assim, sinônimo de pedagogia discursiva. Isso implica a já muito preconizada abertura da aula de língua materna à pluralidade de discursos. Implica, sobretudo, uma forma de tratamento desses discursos que leve o aluno à compreensão e apropriação que possa ser garantia da aquisição de uma competência discursiva.

Segundo Fonseca, numa pedagogia discursiva,

[...] o peso das considerações de ordem ideológica, sociológica, estética não pode, apesar de sua importância, relegar para segundo plano o processo de construção lingüística dos discursos. [...] é imprescindível alargar o seu âmbito (competência discursiva) e conceber a competência lingüística também na sua dimensão textual (apropriação dos mecanismos lingüísticos da construção do texto). [...] Torna-se indispensável considerar, para além da gramática da frase, uma gramática do texto e proceder a uma exploração pedagógica dessa gramática que se oriente para uma ainda mais alargada gramática da comunicação, do funcionamento dos discursos. (FONSECA, 1994, p. 108). (Grifos da autora). 
Isso não significa centrar a preocupação de ensino nas necessidades comunicativas do tipo imediato, pois isso acarretaria ao ensino da língua um caráter "utilitarista" que o empobreceria. Nesse sentido, o ensino de língua materna precisa ser entendido como uma "[...] actividade que se insere num processo de aprendizagem que começou antes da escola, e que continuará para além dela". (FONSECA, 1994, p. 113).

A exploração do texto na aula de língua materna será constituída, assim, fundamentalmente, pela tentativa de levantamento das marcas do processo enunciativo, das ações e interações nele presentes. O levantamento dessas marcas conduzirá à determinação das características específicas dos textos ou da especificidade dos discursos e permitirá o estabelecimento de tipologias.

Segundo Fonseca \& Fonseca (1977), numa análise de textos informada por princípios pragmáticos, não se pode desconsiderar a metalinguagem a utilizar, pois analisar um enunciado verbal é realizar um ato metalinguístico. Numa análise pragmática em que se consideram simultaneamente linguagem e comportamento, precisamos de um tipo novo de metalinguagem que diga respeito não apenas ao enunciado linguístico, mas ao todo da atuação que com aquele perfaz o ato comunicativo. Os autores sugerem que esse tipo de metalinguagem seja denominado metacomunicação, que teria um caráter prévio relativamente a outros tipos de metalinguagem, nomeadamente a de tipo gramatical.

Nas atividades de análise da comunicação que deve ocupar um lugar importante na aula de língua materna, é fundamental a tentativa de sistematização de aspectos que dizem respeito à relação entre a língua e a sua utilização, entre a linguagem e o universo de locutores e seus comportamentos. (FONSECA \& FONSECA, 1977, p. 115).

É a esse tipo de análise que esses autores denominam de análise do funcionamento da linguagem, oportunidade em que se procura ver de que modo o texto está estruturado com funções específicas, representando fundamentalmente "[...] a realização não apenas de um acto locutório (produção de um enunciado conformemente às regras de um sistema gramatical), mas igualmente a um acto ilocutório (orientado para influenciar o comportamento do interlocutor) e de um acto perlocutório (efeito produzido no interlocutor)". (FONSECA \& FONSECA, 1977, p. 117, baseando-se em AUSTIN, 1993).

Obviamente, uma análise que pretende abarcar todos esses aspectos presentes no ato verbal e, desse modo, explícita ou implicitamente concretizados no enunciado, não 
poderá restringir-se aos elementos linguísticos constituintes do texto, antes terá que se alargar à consideração dos dados extra-linguísticos, situacionais. Para isso, é imprescindível, incluir na reflexão metalinguística áreas até hoje bastante marginalizadas ou contempladas de forma fragmentada, dispersa e não estruturada, nomeadamente a semântica frásica e textual. (LOPES, 2005).

O trabalho ao nível do componente semântico da língua permite uma interface permanente entre gramática e discurso e abre perspectivas interessantes ao nível da superação da dicotomia estrutura vs uso, apontando para a pertinência de abordagens sistêmico-funcionais do sistema linguístico.

A compreensão dessas dimensões, segundo Fonseca \& Fonseca (1977), assentará a clara aceitação por parte do professor de Português que implica uma inequívoca tomada de consciência de que adquirir linguagem, desenvolver e estruturar a competência comunicativa significa integração atuante e crítica na práxis social, pois que é na linguagem que o homem se assume, se define, se situa perante o mundo e perante os outros homens e continuamente atua sobre eles. Nessa perspectiva, todas as atividades, na aula de língua materna, estão ligadas à exploração do texto.

Todas elas partem de um texto e/ou conduzem a um texto, pelo que temos bem consciência de que ao propor uma nova forma de explorar o texto, estamos a sugerir algo que vai mexer com todo tipo de actividades didácticas praticadas na aula de língua materna. [...] trata-se, pois, mais do que propor práticas totalmente novas, de sugerir formas de alargamento das práticas já existentes. [...] o mais importante, o mais fecundo, parecenos ser começar por, utilizando os mesmos meios, dar a essa utilização uma intencionalidade diferente e, logo, um diferente rendimento. (FONSECA \& FONSECA, 1977, p. 125).

Por isso muitos autores, partindo de princípios vygotskyanos, defendem a importância da interação verbal no processo de construção da escrita, uma vez que ela permite distribuir a carga cognitiva entre os membros do grupo, verbalizar os problemas que se colocam, deles tendo consciência, e, conjuntamente procurar caminhos para os resolver. Por fim, e relativamente a este último aspecto, favorece a capacidade de falar "sobre" a língua que se está a produzir: "[...] actividade metalingüística que parece imprescindível para o controle dos processos complexos de produção discursivo-textual". (CAMPS, 2003, p. 211).

Segundo Fonseca (1994), o trabalho com um texto analisado pode ser a base de atividades várias e bem conhecidas como reprodução, reescrita, resumo, paráfrase. Com 
muitas variantes possíveis: desconstruir um texto, mudando a ordem das frases e outras unidades constituintes e propor ao aluno que o reconstrua é uma atividade intermediária entre leitura e escrita.

Nessa mesma perspectiva, Pereira (2005) argumenta que é preciso mudar as representações do ato de escrever, erigir para si o postulado de que o saber escrever integra o saber fazer uma leitura crítica do próprio texto. Porém, proceder a uma leitura para apreender o disfuncionamento que integra um dado texto parece colidir com a representação mais comum do ato de ler - obter informação sobre o conteúdo. Desse modo,

[...] tanto a detecção de erros que o texto comporta como depois a activação de estratégias de resolução desses erros de escrita [...] são dificultadas pela necessidade de uma releitura dos textos que o próprio escrevente neutralize informações privilegiadas que detém, mas que o leitor virtual não possui. Segundo Sylvie Plane (1994, p. 52), este aspecto permite-nos compreender os problemas da ambigüidade referencial das retomadas anafóricas em muitos textos dos alunos; estes não fornecem muitas explicações porque não sabem representar para si o desconhecimento daqueles que o lêem. (PEREIRA, 2005, p. 153).

De fato, o que algumas investigações demonstram, segundo essa pesquisadora, é que "só um trabalho sistemático sobre a revisão - reescrita pode ser transformador dos modos de pensamento e acção dos alunos. Para gerar neles a adopção de um verdadeiro olhar crítico sobre os textos que redigem e conseguir que a operação de revisão não seja uma simples operação cosmética ".

Nessa perspectiva, a prática da análise linguística em sala de aula visa à reflexão sobre a linguagem e a direção dessa reflexão tem por finalidade o uso dos recursos expressivos. Por meio dessa construção consciente, o aluno poderá se tornar sujeito de seu dizer e melhor se inserir nesse mundo competitivo. (GERALDI, 1993). Para isso, fazse necessário formar leitores e escritores capazes de compreender e inferir as mensagens que remetem e as que Ihes são endereçadas, é preciso ter cidadãos com um domínio mais amplo das atividades de leitura/releitura, escritura/reescritura de textos, fazendo uso adequado das normas linguísticas. É preciso que haja diálogo entre texto e autor. Será por meio da mediação do professor que o aluno melhor poderá se desenvolver enquanto autor de seus próprios textos.

Agindo assim, segundo Conceição Aparecida de Jesus (1998, p.100), temos a valorização do texto do aluno, à medida que, sujeitos e textos realizam-se na ação, no 
trabalho sobre e pela escrita. Faz-se necessário considerar a relevância dos problemas linguísticos apresentados conforme a plenitude dos objetivos do texto, obtida na sua dialogicidade com o conjunto dos interlocutores.

Enfim, centrada na reestruturação, a prática de análise linguística/reflexão sobre a língua é parte das práticas de letramento escolar, consistindo numa reflexão explícita e sistemática sobre a constituição e o funcionamento da linguagem nas dimensões sistêmica (ou gramatical), textual, discursiva e também normativa, com o objetivo de contribuir para o desenvolvimento de habilidades de leitura/escuta, de produção de textos orais e escritos e de análise e sistematização dos fenômenos linguísticos. (MENDONÇA, 2006).

Isso seria de suma importância, pois o que nossos estudantes mais precisam é saber manusear uma língua viva, flexível e criadora, adaptável às necessidades vitais, intelectuais, afetivas que colabore decisivamente na construção de sua personalidade, de sua imaginação, de seus princípios. No entanto, segundo Mateus (2002, p. 82), "pode afirmar-se que a transformação operada não acompanhou o progresso da investigação: o ensino da língua oscila ainda hoje, frequentemente, entre uma imposição de conceitos tradicionais e uma transmissão dos últimos resultados de investigação linguística".

\section{As atividades de análise linguísticas são efetivadas nas práticas escolarizadas?}

Mediante o exposto, verificaremos algumas produções escritas já corrigidas por um professor do $5^{\circ}$ ano do ensino fundamental, objetivando entender que diálogo tem realizado com seu aluno para que ele possa ampliar sua competência comunicativadiscursiva. O professor ao devolver o texto corrigido para seu aluno oferece pistas para que ele possa refletir sobre a sua escrita? Ampliar a informatividade do texto, a argumentatividade e a coerência textual?

Observando os textos desses alunos (T1 e T2, em anexo), pudemos verificar que o professor proporciona momentos de produção textual semanalmente, após leitura e discussão prévia sobre a temática. O professor demonstra se preocupar com o fato de que os alunos tenham o que dizer em suas produções escritas.

O primeiro texto analisado (T1, p. 17) foi elaborado após leitura e discussão do conto "João e o pé de feijão". O professor solicita que se produza um texto com o título "A princesa e o feijão mágico". Após o título sugerido pelo professor, esperava-se que o aluno dialogasse com os contos de fadas, mas neste texto, o autor de T1 vai além do mundo dos contos tradicionais, traz para sua história, o discurso dos programas infantis 
atuais "[...] tinha um castelo chamado Castelo Ratimbum", que deve fazer parte do cotidiano desse autor. Em suma, podemos afirmar que

[...] os fatos, dados do mundo, trazidos para o discurso, exercem mais que uma simples função informativa, eles são agenciados pelo locutor em função de seus objetivos e esta ação os transforma em dois sentidos: de um lado porque são apresentados como uma construção específica do real; do outro lado porque se transformam, no discurso, em argumentos, a favor do ponto de vista que o locutor pretende defender. (GERALDI, 1993, p. 3).

No entanto, como podemos verificar na produção já corrigida pelo professor, não há uma mediação no sentido de o aluno ampliar idéias. Não há recomendação para que o aluno volte à sua produção para reler e refletir sobre o que escreveu, ele corrige os problemas de grafia e pontuação e solicita que reescreva algumas palavras grafadas de forma equivocada. Nota-se que esse professor se prende muito à grafia de letras maiúsculas e minúsculas, a falta de alguma letra que, provavelmente, o autor esquecera de grafar e a questão da pontuação no discurso direto.

Como não há o trabalho de reelaboração, a atividade de escrita morre aqui, não há releitura do texto produzido por parte do aluno para que ele possa refletir sobre a melhor forma de se usar o discurso direto, não há troca de textos entre os pares para que haja um maior diálogo sobre a produção de cada um. O texto para esse professor e, consequentemente, para o aluno, é um produto pronto e acabado, a incompletude parece não existir.

É importante salientar que o fato de o professor apontar com a caneta vermelha os problemas ortográficos, não significa que o aluno vá rever suas inadequações de escrita. A falta de uma orientação sobre como amenizar tais problemas faz com que o aluno continue carregando os mesmos problemas de escrita.

Sabemos que a prática de análise linguística se caracteriza por um debruçar sobre os modos de ser da linguagem e isso pode ocorrer tanto no interior da prática de leitura como na de produção textual, trata-se de buscar ou perceber os recursos expressivos e processos de argumentação que se constituem na dinâmica da atividade linguística, isso porque o objetivo principal da análise linguística é a construção de conhecimento (reconhecimento só é legítimo na medida em que participa de um processo de construção do conhecimento). (BRITTO, 1997, p. 164). 
Observando a segunda proposta de produção (T2, p. 18-19), denominada "futebol ao vivo", bem como a produção final desse mesmo aluno, verifica-se que ele consegue narrar bem o momento do jogo de futebol, desenvolve sua atividade segundo 0 recomendado pelo professor, utiliza-se dos verbos de ação sugeridos com bastante propriedade. É um assunto significativo para ele, por isso consegue colocar emoção em sua narração. Afinal, essa produção, segundo a professora, acontecera numa segundafeira, após eles terem assistido a um jogo de futebol pela TV.

No entanto, verifica-se que apesar de o aluno ter o que dizer em sua produção escrita, não há um trabalho de releitura sobre o que escreveu, não há interlocução entre os pares, não há elogios à criatividade e estilo.

Portanto, apesar de toda criatividade do aluno, o que é apontado é a recorrência dos problemas ortográficos - a questão do uso da letra maiúscula e outros problemas ortográficos apresentados no texto anterior -, como o aluno não refletiu sobre os problemas anteriores, continuou com o mesmo problema neste texto.

A narrativa que fora relatada de forma viva, dinâmica, acelerada (por isso a ausência de pontuação) é corrigida pelo professor que assinala a falta de pontuação, tirando, assim, a sonoridade do relato vivo do jogo. Observa-se que o aluno apenas por ouvir esse gênero textual, consegue transpor suas características para sua produção, mas a escola desconsidera essas características e aponta como inadequação a falta de pontuação. Assim, a audácia, a criatividade e a expressividade do aluno é podada, silenciada.

Ora, textos produzidos de forma semelhante por autores consagrados são considerados literários, modelares do gênero textual "relato de um jogo de futebol". Já o aluno, ao fazer algo parecido, é considerado "erro". Para ilustrar essa passagem, trago como exemplo uma narrativa de Lia Zatz, Zilzinho, considerado um exemplo do gênero relato de jogo de futebol, bastante explorado na escola devido ao estilo, criatividade, pontuação e sonoridade.

\section{Zilzinho (Lia Satz)}

Zero a zero que zebra o time já não tem gás o tempo é fugaz o juiz vai finalizar que azar Zinho não desistiu faz o sinal da cruz buscando luz e zarpa com rapidez bola no pé e que clareza desliza esvazia a defesa e que beleza um chute cruzado mas sem diretriz que infeliz por um triz é sem juízo esse Zinho só tem verniz vai passar pó-de-arroz vai ser atriz a galera tá que tá zangada exaltada enfezada e com razão quer dar vazão arma o banzé exige desempenho e desempata um golzinho só unzinho faz a fineza seu juiz de desonrar sua origem inglesa atrase o relógio mostre 
grandeza e lá vai o Zinho de novo sozinho solta essa bola rapaz não seja voraz mas que esperteza que braveza é esse rapaz é um faz tudo

em zigue-zague

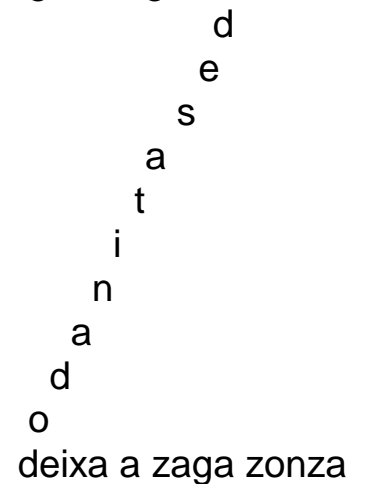

pra trás tá na cozinha e zás-trás gol BRAZIL ZIL ZINHO!!!!

Este texto seria um exemplo de texto vivo, dinâmico, que o professor poderia explorar em sala de aula toda a riqueza do relato do jogo de futebol, do estilo da autora, da literariedade do texto, da expressividade da poesia concretista - que se deu pela quebra de linearidade com a palavra "zigue-zague" cortando a linearidade da leitura do texto, diminuindo-lhe o ritmo (como faz um locutor de rádio)-, intensificando o som com a fusão gráfica e fonética de Brasil/Zil/Zinho.

No entanto, ao invés de levar um texto como este para a sala de aula para que o aluno pudesse refletir sobre a estrutura desse texto, bem como as formas linguísticas utilizadas, o professor continua com suas correções formais, sem levar o aluno a ampliar seu repertório linguístico-discursivo, sem oportunizar momentos para a reflexão e reelaboração sobre as diversas formas de dizer, de se enunciar esse mesmo texto, de dialogar com os diversos textos de nossa cultura.

Nesse sentido, defendo o princípio de que é preciso levar o aluno a reelaborar o que escreveu, transformar e refletir sobre sua escrita, pois assim ele estará trabalhando com a gramática em uso, a partir de suas próprias dificuldades. E esses são os pressupostos da teoria de Análise linguística proposta por Geraldi (1984).

Obviamente, na manipulação objetiva e engajada da linguagem, em suas variedades e registros, orais e escritos, os sujeitos da linguagem constroem um saber sobre ela, tanto no que diz respeito às categorias semânticas, quanto às categorias formais. Constroem, assim, um saber que é gramatical e social ao mesmo tempo. A inclusão de um vocabulário técnico resulta na necessidade prática dos próprios agentes do processo pedagógico. Dessa forma, a atividade não se caracteriza como 
metalingüística, porque não tem por finalidade primeira a construção de uma teoria sobre a linguagem. (BRITTO, 1997, p. 165).

\section{Considerações finais}

Será por meio da prática de análise linguística que o professor poderá mostrar a seu aluno como o texto se organiza, a partir de quais elementos gramaticais (pronomes, advérbios, conjunções) se dá a costura entre as partes. Segundo Pisciotta (2000, p.94), essas atividades são aquelas em que "o aluno exercita a reflexão sobre fatos textuais e linguísticos. Ele observa as particularidades das ocorrências, faz comparações, transforma as frases e explora criativamente os recursos gramaticais a fim de melhorar a expressividade no discurso".

Um trabalho dessa forma, segundo Silva, Moysés, Fiad e Geraldi (1986, p. 69), deixa de ser a gramática imposta e inacessível para ser de todos, e, os professores deixam de trabalhar somente com textos e exemplos modelares de língua (oral e escrita) para trabalhar com textos produzidos pelos alunos no sentido de descobrir suas hipóteses sobre a língua e confrontá-las umas com as outras e com a convenção.

Desse modo, a figura do autor/leitor passa a ser vista como a de um agente mobilizador, cujas palavras são propulsoras de ações historicamente constituídas e, portanto, não podem ser apagadas, corrigidas, substituídas, pontuadas e/ou reelaboradas para atender exclusivamente aos reclames imediatos da gramática pela gramática, como ocorreu em T1 e T2, isso porque temos de privilegiar o sentido, a compreensão do que se faz com a linguagem, o porquê de o autor do texto se expressar dessa ou daquela forma.

\section{Referências}

ANTUNES, I. Muito além da gramática: por um ensino de línguas sem pedras no caminho. São Paulo: Parábola editorial, 2007.

BRASIL. Parâmetros Curriculares Nacionais: terceiro e quarto ciclos do Ensino

Fundamental: Língua Portuguesa. Brasília: MEC/SEF, 1998.

BRITTO, L. P. L. A sombra do caos: ensino de línguas $x$ tradição gramatical. Campinas, 1997.

DOLZ, J. \& SCHNEUWLY, B. Gêneros e progressão em expressão oral e escrita. In: ROJO, H. R., CORDEIRO, G. (Org.). Gêneros orais e escrito na escola. Campinas: Mercado de Letras, 2004.

FIGUEIREDO, O. Didáctica do Português língua materna dos programas de ensino às teorias, das teorias às práticas. Porto: Edições ASA, 2005.

FRANCHI, C. Mas o que é mesmo "gramática"?. São Paulo: Parábola Editorial, 2006. 
Mas o que é mesmo "gramática"?. In: São Paulo (Estado). Secretaria de Educação. Coordenadoria de Estudos e Normas Pedagógicas. Língua Portuguesa: o currículo e a compreensão da realidade. São Paulo: SE/CENP, 1991, p. 43-59. 45,1987. Criatividade e gramática. Trabalhos em Lingüística Aplicada. № 9, p.5-

GERALDI, J. W. O texto na sala de aula. Cascavel: Assoeste, 1984.

Portos de passagem. 2. ed. São Paulo: Martins Fontes, 1993.

Linguagem e ensino: Exercícios de militância e divulgação. Campinas:

Mercado de Letras, 1996.

O texto na sala de aula. 2. reimp. São Paulo: Ática, 1997.

ILARI, R. \& BASSO, R. O português da gente: a língua que estudamos, a língua que falamos. São Paulo: Contexto, 2006.

JESUS, C. A. Reescrevendo o texto: a higienização da escrita. In: CHIAPPINI, L. (Org.). Aprender e ensinar com textos de alunos. 2. ed. São Paulo: Cortez, 1998. p. 99-118. (Coleção aprender e ensinar com textos, vol. 1).

MAGNANI, M. R. Em sobressaltos: formação de professora. Campinas: Editora da Unicamp, 1996.

MARTINS, S. A. F. M. O professor iniciante e o seu trabalho com o texto na sala de aula. Tese de Doutorado, UNESP/Assis, 2002.

MATEUS, M. H. M. A face exposta da língua portuguesa. Lisboa: Imprensa Nacional Casa da Moeda, 2002.

MENDONÇA, M. Análise lingüística no ensino médio: um novo olhar, um novo objeto. In: BUZEN, C. \& MENDONÇA, M. Português no ensino médio e formação do professor. São Paulo: Parábola Editorial, 2006.

PEREIRA, M. L. A. Escrever em Português didácticas e práticas. Porto: Edições ASA, 2000.

PISCIOTA, H. Análise lingüística: do uso para a reflexão. In: Brito, E. B. (org.). PCNs de Língua Portuguesa: a prática em sala de aula. São Paulo: Arte \& Ciência, 2001.

POSSENTI, S. Gramática e política. In: O texto na sala de aula. São Paulo: Ática, 1997. p. 47-56.

Por que (não) ensinar gramática na escola? Campinas: Mercado de Letras, 


\section{Anexos}

TEXTO 1 = (T1)

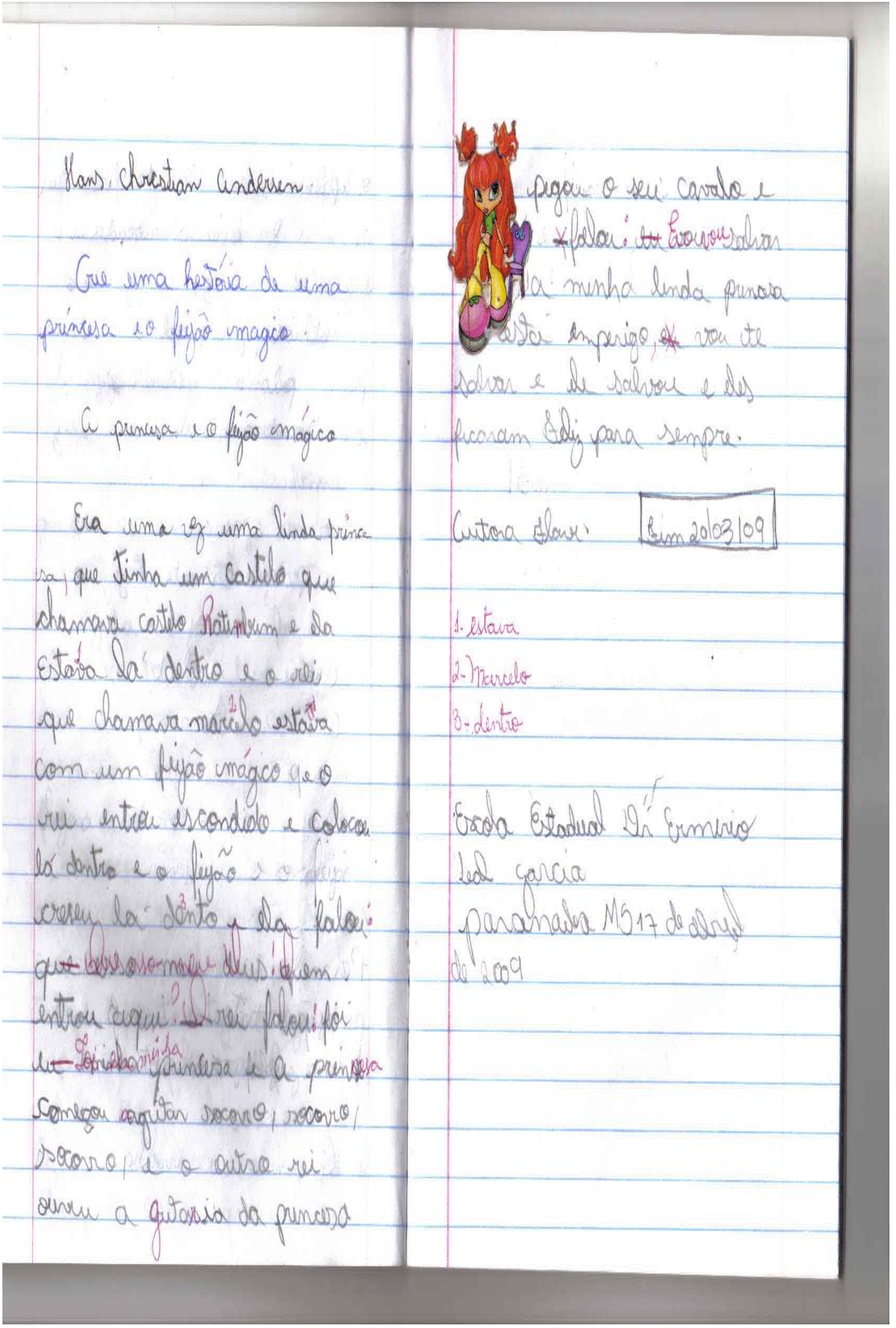


TEXTO 2 (T2)

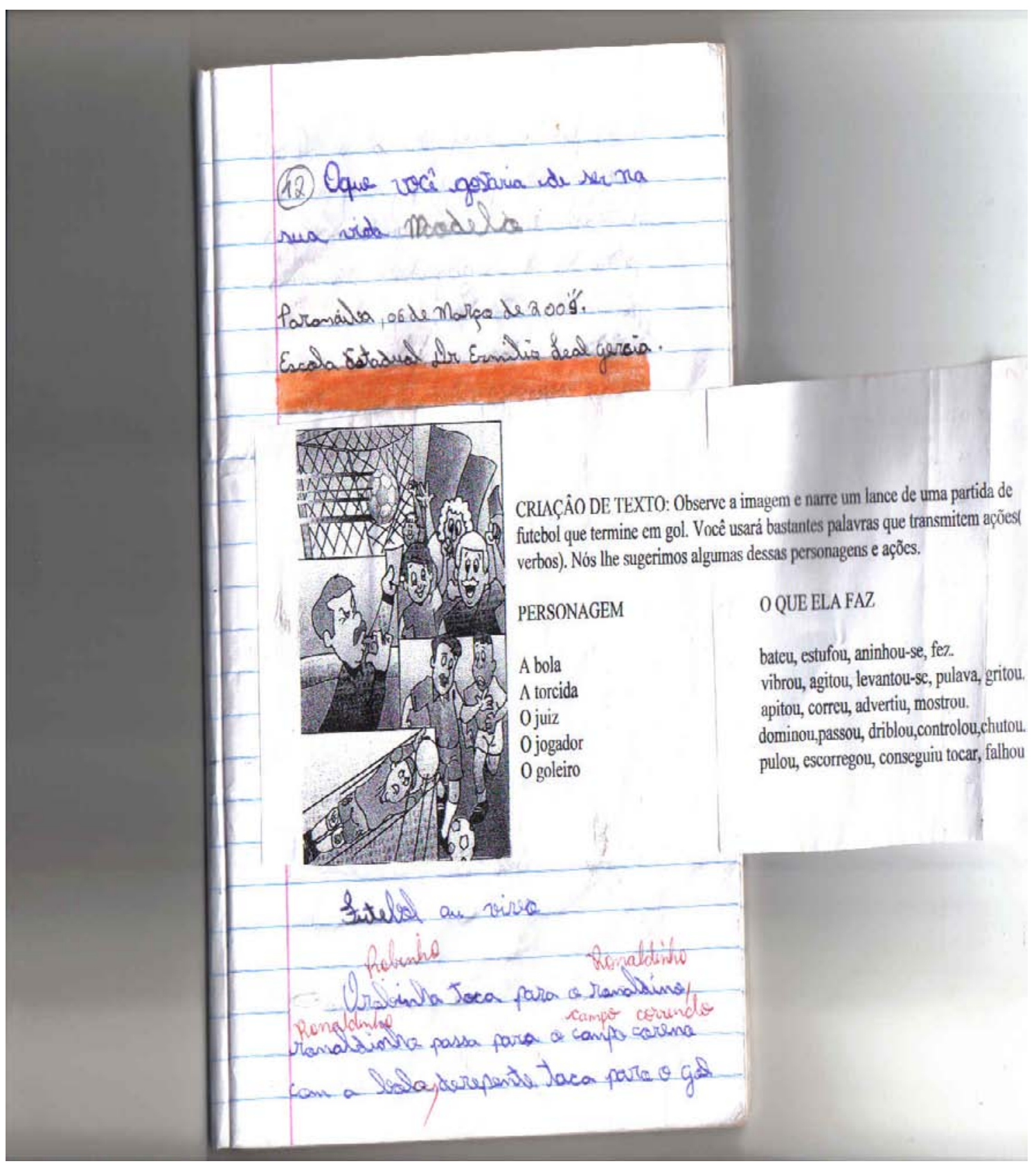




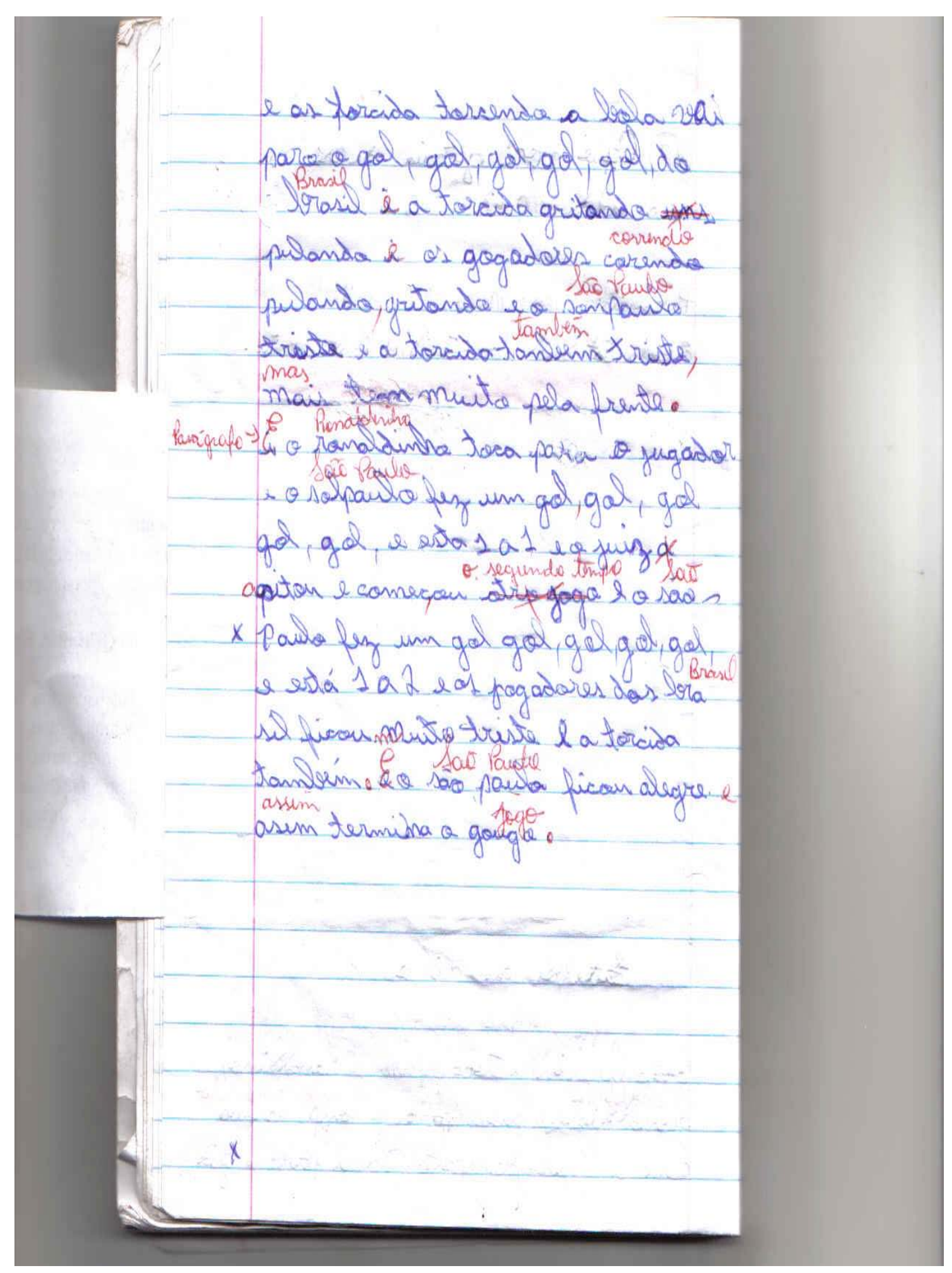

